\title{
Rapid Access to Diverse Potassium Acyltrifluoroborates (KATs) Through Late-Stage Chemoselective Cross-Coupling Reactions
}

Xingwang Deng ${ }^{1}$, Guan Zhou $^{1}$, Xiao Han ${ }^{1}$, Khadim Ullah ${ }^{1}$, Rajavel Srinivasan*,1,2

${ }^{1}$ School of Pharmaceutical Science and Technology (SPST), Tianjin University, Building 24, 92 Weijin

Road, Nankai District, Tianjin 300072, P. R. China; E-mail: rajavels@tju.edu.cn

${ }^{2}$ Singapore Eye Research Institute, The Academia, 20 College Road, Discovery Tower, Singapore 169856,

Singapore.

\begin{abstract}
Potassium acyltrifluoroborates (KATs) are opening up new avenues in chemical biology, materials science and synthetic organic chemistry due to their intriguing reactivities. However, the synthesis of these compounds remains mostly complicated and time-consuming. This lack of a rapid and facile synthetic route has hindered the widespread adoption of KAT-based chemistry, especially in the areas of compound library synthesis and drug discovery. Herein, we have developed chemoselective Pd-catalyzed approaches for the late-stage diversification of arenes bearing pre-functionalized KATs. These approaches feature chemoselective cross-coupling, rapid diversification, functional group tolerance, mild reaction conditions, and high yields.
\end{abstract}

\section{INTRODUCTION}

Acylborons are an emerging class of organic compounds, which have untapped potential as a new synthetic tool in a myriad of research areas. ${ }^{1}$ Potassium acyltrifluoroborates (KATs) are the stable version of acylborons which are generally free-flowing solids that tolerate air and water, and possess unique reactivity patterns. ${ }^{2}$ For example, KAT reacts chemoselectively with hydroxylamine under mild aqueous conditions to form a stable amide linkage in a reaction referred to as KAT ligation, which was pioneered by Bode. ${ }^{3}$ KATs also react with secondary amines under mild condition to furnish trifluoroborate-iminiums (TIMs), which are novel synthetic intermediates to make $\alpha$-aminotrifluoroborates. ${ }^{4}$ Further, the applications of KATs are ever expanding in the areas of materials science and chemical biology. ${ }^{5}$ However, rapid methods to access libraries of KAT compounds are still in demand. Such methods would enable the application of KATs in compound library synthesis and fragment-based drug discovery. ${ }^{6}$

In general, KATs and other acylborons can be prepared by the following approaches: (1) quenching a boron electrophile, such as $\mathrm{B}(\mathrm{OMe})_{3}$, with an acyl anion equivalent; ${ }^{2 a}$ (2) treating an organometallic compound, such as ArLi or an alkyl cuprate species with a thioformamide-based KAT transfer reagent; ${ }^{2 b}, 2 c(3)$ addition of a nucleophilic boron source to an electrophilic carbon 
center; ${ }^{7}(4)$ oxidation of pre-functionalized organoboron compounds; ${ }^{2 f,}{ }^{8}(5)$ Pd-catalyzed MigitaKosugi-Stille cross-coupling between a tin reagent and an aryl iodide. ${ }^{2 d}(6)$ Ring opening reaction of $\alpha$-chloroepoxyboronates. ${ }^{9}$ (7) Cu-catalyzed carbonylative borylation of alkyl halides. ${ }^{10}$ Herein we disclose chemoselective $\mathrm{Pd}$-catalyzed approaches for the late-stage diversification of haloarenes bearing pre-functionalized KATs. These approaches enabled quick and easy access to a diverse range of KATs that were previously unknown.

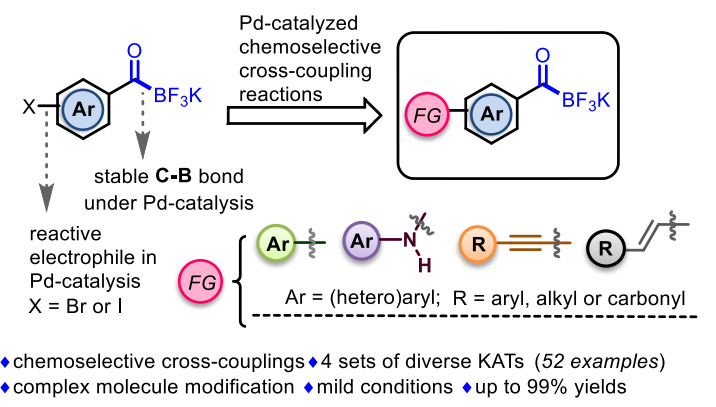

Figure 1: Rapid access to diverse KATs using chemoselective cross-coupling reactions

\section{RESULTS AND DISCUSSIONS}

It was reported that (2-phenylacetyl)trifluoroborate was not a viable substrate for Suzuki-Miyaura crosscoupling to synthesize ketones, ${ }^{2 \mathrm{e}}$ following this result, we investigated an array of Pd-catalyzed crosscoupling reactions on aryl bromides/iodides pre-functionalized with KATs to explore the possibility of rapid diversification. At the outset of the study we investigated the Suzuki-Miyaura coupling of commercially available potassium 4-bromobenzoyltrifluoroborate (1a) with 4-chlorophenylboronic acid. A series of conditions were screened to find out the optimal reaction conditions in which the $\mathrm{C}-\mathrm{B}$ bond on the KAT 1a (Figure 2) remained intact whilst the $\mathrm{C}$ - $\mathrm{B}$ of the 4-chlorophenyl boronic acid participated in the cross-coupling with C-Br of KAT 1a (refer SI, Table S1). $\mathrm{Pd}(\mathrm{dppf}) \mathrm{Cl}_{2} \cdot \mathrm{CH}_{2} \mathrm{Cl}_{2}$ was identified as a suitable catalyst but XPhos Pd G3 performed even better for a greater range of substrates. The reaction proceeded smoothly in 1,2-dimethoxyethane (DME) and in the presence of water as co-solvent. $\mathrm{K}_{2} \mathrm{CO}_{3}$ was elected as the base. Having optimized the reaction conditions we choose a diverse array of boronic acid substrates to make biaryl KATs on reaction with KATs 1a-1e (Figure 2).<smiles>[X]c1ccc(C(=O)Br)cc1</smiles>

$1 \mathrm{a}, \mathrm{X}=\mathrm{Br}$ $1 c, X=I$<smiles>[X]c1cccc(C(=O)Br)c1</smiles>

$1 b, X=B r$ 1d, $X=$ I<smiles>O=C(Br)c1ccc(Br)s1</smiles>

$1 e$

Figure 2: KAT building blocks used in this study 

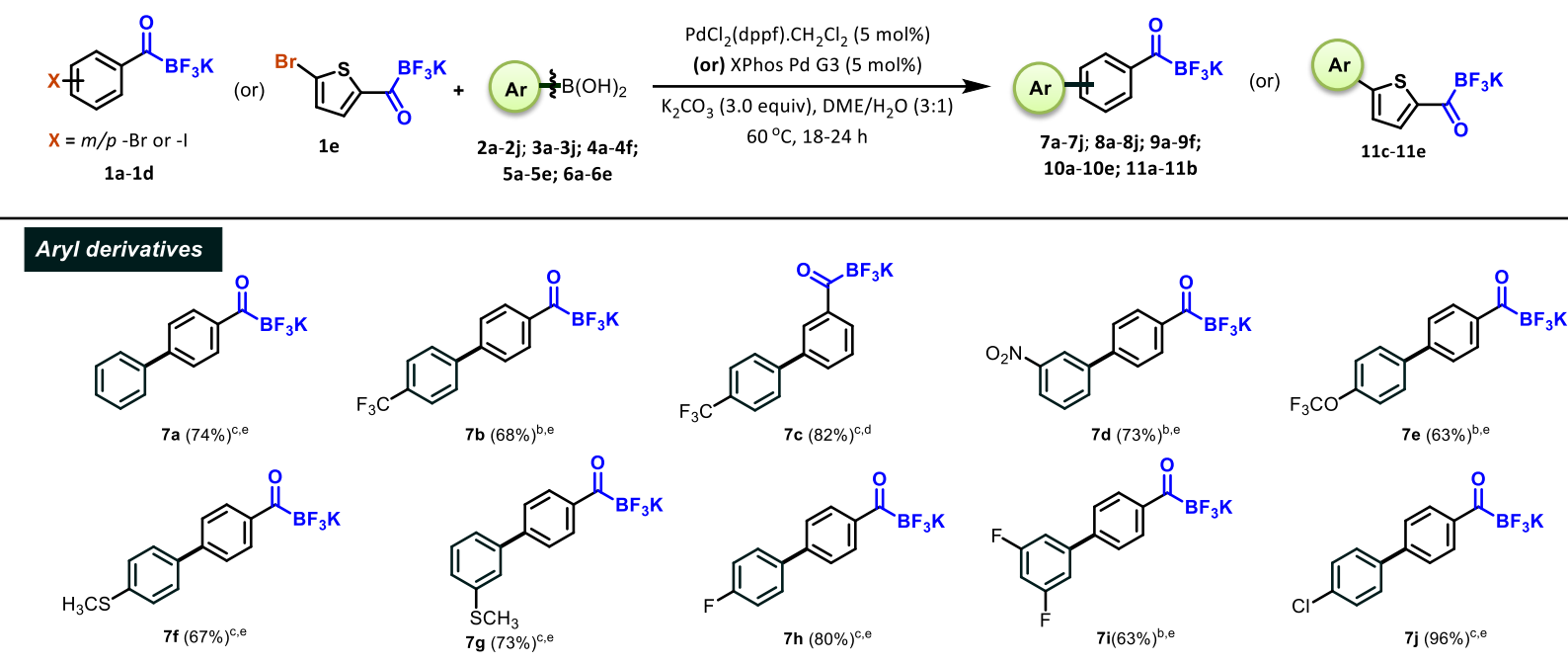

\section{Bifunctional KATs}<smiles>N#Cc1ccc(-c2ccc(C(=O)[Br+])cc2)cc1</smiles>

$8 \mathbf{a}(72 \%)^{\mathrm{c}, \mathrm{e}}$<smiles></smiles>

$8 b(65 \%)^{b, e}$<smiles>O=C(Br)c1ccc(-c2cccc(O)c2)cc1</smiles><smiles></smiles>
$8 f(83 \%)^{c, 9}$<smiles>CC(=O)c1ccc(-c2ccc(C(=O)[Br+2])cc2)cc1</smiles><smiles>COC(=O)c1ccc(-c2ccc(C(=O)Br)cc2)cc1</smiles><smiles>C[Si](C)(C)c1ccc(-c2ccc(C(=O)[Br+])cc2)cc1</smiles><smiles>[X]C(Br)(Br)c1cccc(-c2cccc(O)c2)c1</smiles><smiles>O=C(Br)c1ccc(-c2ccc(CO)cc2)cc1</smiles><smiles>O=C(Br)c1cccc(-c2ccc(CO)cc2)c1</smiles>

\section{Heteroaryls}<smiles>O=C(Br)c1ccc(-c2cccnc2)cc1</smiles>

9a $(94 \%)^{c, 9}$<smiles>O=C(Br)c1ccc(-c2cccnc2F)cc1</smiles>

$9 b(66 \%)^{b, e}$<smiles>O=C(Br)c1ccc(-c2ccsc2)cc1</smiles>

$9 c(80 \%)^{\mathrm{c}, \mathrm{e}}$<smiles></smiles>

9d $(60 \%)^{b, e}$<smiles>O=C(Br)c1cccc(-c2cnc3ccccc3c2)c1</smiles>

$9 e(99 \%)^{c, f}$

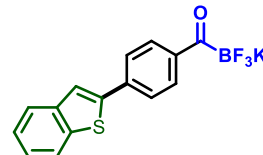

9f $(74 \%)^{\mathrm{b},}$<smiles>O=C(Br)c1ccc(-c2ccc3ccccc3c2)cc1</smiles>

$10 \mathrm{a}(69 \%)^{\mathrm{b}, \mathrm{e}}$<smiles>CC(C)(C)C1c2ccccc2-c2ccc(-c3ccc(C(=O)[18F])cc3)cc21</smiles><smiles>O=C(O)c1cccc(-c2ccc(-c3ccccc3)cc2)c1</smiles>

10d $(99 \%)^{c, t}$<smiles></smiles>

$10 \mathrm{e}(43 \%)^{\mathrm{b}, \mathrm{e}}$

\section{Natural product derivatives}

Thiophene-based KATs

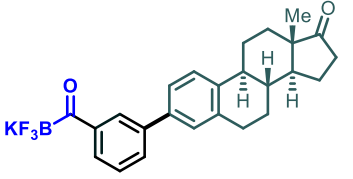

11a $(51 \%)^{\mathrm{c}, \mathrm{f}}$

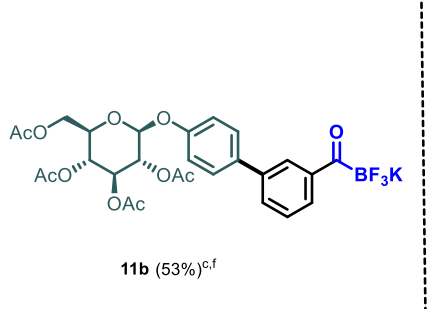<smiles></smiles>

$11 \mathrm{c}(98 \%)^{\mathrm{h}}$<smiles>C[13C](=O)c1ccc(-c2ccc(S(C)(C)C)cc2)s1</smiles>

11d $(97 \%)^{\mathrm{h}}$<smiles>NC(=O)c1ccc(-c2ccc3ccccc3c2)s1</smiles>

$11 \mathrm{e}(95 \%)^{\mathrm{h}}$

aReaction conditions: KAT $1(0.15 \mathrm{mmol})$, boronic acids 2-6 (1.01 -1.5 equiv.), palladium catalyst $\left(5 \mathrm{~mol}_{0}\right), \mathrm{K}_{2} \mathrm{CO}_{3}(3.0$ equiv.), $\mathrm{DME} / \mathrm{H}_{2} \mathrm{O}(3: 1,2 \mathrm{~mL}), 60{ }^{\circ} \mathrm{C}, 18-24 \mathrm{~h}$. ${ }^{\mathrm{b} P d C l} \mathrm{Pdpl}_{2}$ (dpp) was used. ${ }^{c} \mathrm{XPhos} \mathrm{Pd}$ G3. dPotassium 3bromobenzoyltrifluoroborate $\mathbf{1 b}$ was used. ePotassium 4-bromobenzoyltrifluoroborate $\mathbf{1 a}$ was used. ${ }^{\mathrm{f}}$ Potassium 3iodobenzoyltrifluoroborate 1d was used. gPotassium 4-iodobenzoyltrifluoroborate 1c was used. chThiophene KAT 1e was used.

Scheme 1: Scope of chemoselective Suzuki cross-coupling with diverse aryl boronic acids 
The first set of aryl boronic acid substrates possessed a variety of functional groups with different electronic effects, including $\mathrm{CN}, \mathrm{CF}_{3}, \mathrm{NO}_{2}, \mathrm{OCF}_{3}, \mathrm{SCF}_{3}, \mathrm{~F}$, and $\mathrm{Cl}$. All these functionalities were well tolerated in the coupling and the corresponding biaryl KATs (7a-7j) were isolated in $63 \%-96 \%$ yields. The next set of substrates for the Suzuki coupling were selected to deliver bifunctional KATs, which could be potentially used for incorporating KATs into complex biomolecules and chemical probes via chemoselective reactions. KATs $(\mathbf{8 a}-\mathbf{8 j})$ bearing reactive functional groups, including $\mathrm{CN}$, alkene, ketone, ester, trimethylsilyl, $\mathrm{OH}$, and $\mathrm{CH}_{2} \mathrm{OH}$ groups that are amenable to chemoselective modifications in the presence of the KAT functionality, were successfully synthesized with yields ranging from $64 \%$ to $99 \%$. These results further demonstrated the simplicity of our approach in introducing orthogonal reactive handles to KATs in a single step; thus, expanding the repertoire of bifunctional KAT reagents.

Next, we investigated the boronic acid derivatives of privileged heterocycles, including pyridine, quinoline, thiophene, and benzothiophene, as coupling partners with the arenes $\mathbf{1 a}$, $\mathbf{1 c}$, and $\mathbf{1 d}$. The desired heterocyclic frameworks bearing KATs 9a-9f were successfully obtained in 60\%-99\% yields. Pyrene, fluorene, and other conjugated $\pi$-arenes, such as naphthalene, are useful structural motifs in organic materials. Functionalizing these scaffolds with KATs can broaden the application of KAT chemistry in the area of materials science. Hence, we investigated $\pi$-arenes functionalized with boronic acid 5a-5e and carried out the Suzuki coupling with the KAT 1a or 1d. Substrates 5a-5d smoothly underwent the Suzuki coupling to furnish the KAT derivatives 10a-10d in 63\%-99\% yields. Pyrene-1-boronic acid 5e afforded the desired KAT 10e in $43 \%$ yield. We were also pleased to observe that the boronic acid derivatives of natural products, such as the estrone $\mathbf{6 a}$ and sugar $\mathbf{6 b}$, underwent the Suzuki coupling with the KAT building block $\mathbf{1 d}$ to afford the respective KAT derivatives $11 \mathrm{a}$ and $\mathbf{1 1 b}$ in $50 \%$ and $53 \%$ yields, respectively, demonstrating the application of this method to complex molecule modification. Finally, thiophene KAT 1e was treated with 3 different aryl boronic acids. We were impressed to see this heteroaryl KAT reacted smoothly with these boronic acids to furnish the respective thiophene-based biaryl KATs 11c to 11 e in $95 \%$ to $98 \%$ yields.

Subsequently, Buchwald-Hartwig amination was explored using the KAT building blocks to establish a $\mathrm{C}\left(\mathrm{sp}^{2}\right.$ )-NHAr linkage (Scheme 2). A 2 mol\% of XPhos Pd G3 precatalyst was successfully able to catalyze $\mathrm{C}\left(\mathrm{sp}^{2}\right)-\mathrm{N}$ bond formation between the KAT building block $1 \mathrm{a}$ or $\mathbf{1 d}$ and various anilines $\mathbf{1 2 a} \mathbf{- 1 2} \mathbf{i}$ to afford KATs 13a-13i in high yields. $\mathrm{K}(t-\mathrm{OBu})$ was found to be compatible with the KAT functionality (see SI, Table S2 for optimization of reaction conditions). It was noted that the KAT functionality remained intact during the amination reaction and the formation of TIM derivatives did not occur with the anilines. However, the use of aliphatic amines, such as cyclohexylamine, morpholine and $n$-butylamine did not afford the desired products, and the recovery of the KAT starting material was unsuccessful. 

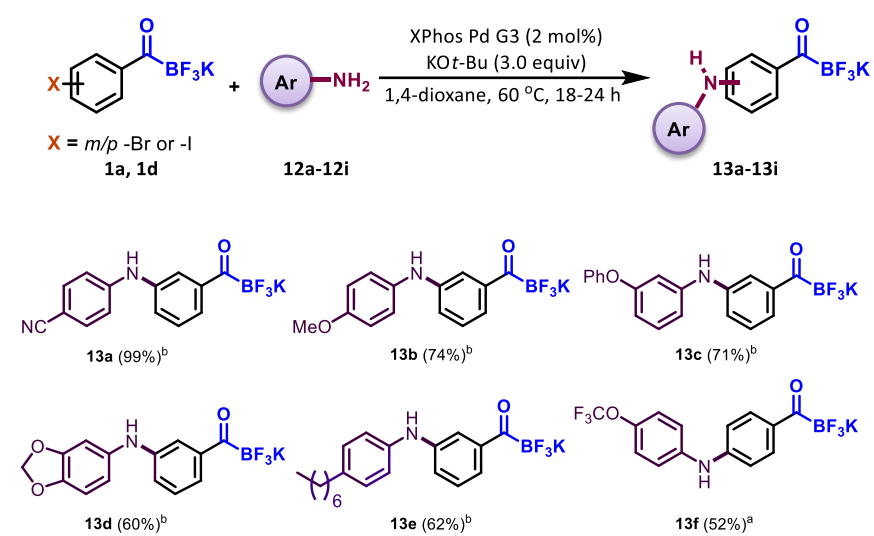

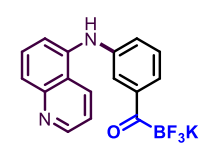

$13 \mathrm{~g}(99 \%)^{\mathrm{b}}$

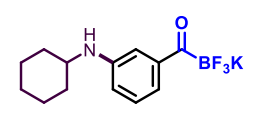

$13 \mathrm{j}(0 \%)$

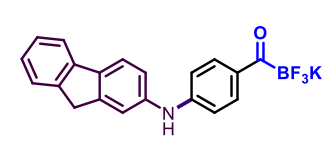

$13 \mathrm{~h}(58 \%)^{\mathrm{a}}$

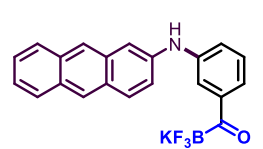

$13 \mathbf{i}(90 \%)^{\mathrm{a}}$
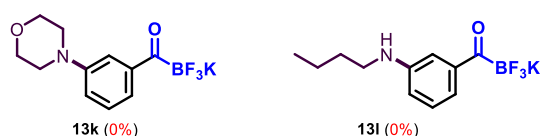

Reaction condition: KATs building block 1a or $1 \mathbf{d}(0.15 \mathrm{mmol}$ ), aniline 12 (a-i) (1.5 equiv.), XPhos Pd G3 (2 mol\%), potassium tert-butoxide (3.0 equiv.), $1.4-$ dioxane $(2 \mathrm{~mL}), 60^{\circ} \mathrm{C}, 18-24 \mathrm{~h}$; aPotassium 4- bromobenzoyltrifluoroborate, 1a was used. bPotassium 3-iodobenzoyltrifluoroborate, 1d was used

Scheme 2 Buchwald-Hartwig cross-coupling reaction on KATs.

Standard Sonogashira coupling

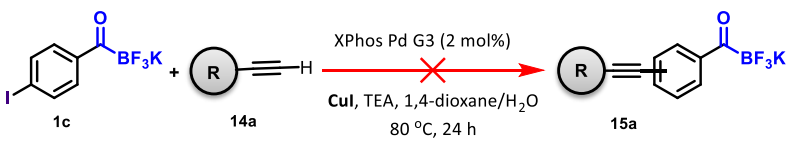

Copper-free Sonogashira coupling

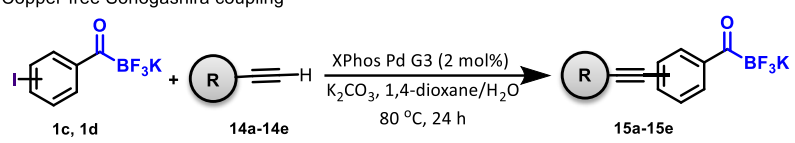

(l)

$15 a(88 \%)^{b} \quad 15 b(98 \%)^{a}$

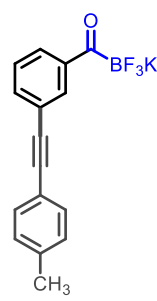

$15 \mathrm{c}(80 \%)^{\mathrm{a}}$<smiles>O=C(c1ccc(C#Cc2ccc(Cl)cc2)cc1)C(Br)(Br)Br</smiles><smiles>O=C(Br)c1cccc(C#CCO)c1</smiles>

$15 d(64 \%)^{b}$

$15 \mathrm{e}(99 \%)^{\mathrm{a}}$

Reaction conditions: KAT 1c or $1 \mathrm{~d}(0.15 \mathrm{mmol})$, alkyne 14 (1.5 equiv.), XPhos Pd G3 (2 mol\%), potassium carbonate (3.0 equiv.), 1,4-dioxane/water ( 2 mL, 3:1), $80{ }^{\circ} \mathrm{C}$, 24h. aPotassium 3- iodobenzoyltrifluoroborate, 1c was used. ${ }^{b}$ Potassium 4-iodobenzoyltrifluoroborate, $1 \mathrm{~d}$ was used.

Scheme 3 Sonogashira cross-coupling on KAT building blocks

Next, we explored the compatibility of the KAT building blocks $\mathbf{1 c}$ and $\mathbf{1} \mathbf{d}$ under Sonogashira coupling conditions. The standard coupling conditions, which use a copper co-catalyst and organic base, did not 
work in our hands and the KAT starting material was decomposed to unidentified impurity. Hence, we screened a number of reaction conditions (see SI, Table S3) and identified a copper-free version of the reaction to be optimal in effecting the transformation whilst maintaining the KAT functionality intact. The optimized conditions used the XPhos Pd G3 catalyst and $\mathrm{K}_{2} \mathrm{CO}_{3}$ as the base. The use of water as a cosolvent increased the reaction yield. Under the optimized conditions, the phenyl acetylenes 14a-14d were successfully coupled to the KAT building blocks $1 \mathrm{c}$ and/or $1 \mathrm{~d}$ to furnish the corresponding products $15 \mathrm{a}-$ 15d) in 68\%-98\% yield, and propargyl alcohol 14e furnished the desired KAT 15e in quantitative yield (Scheme 3).

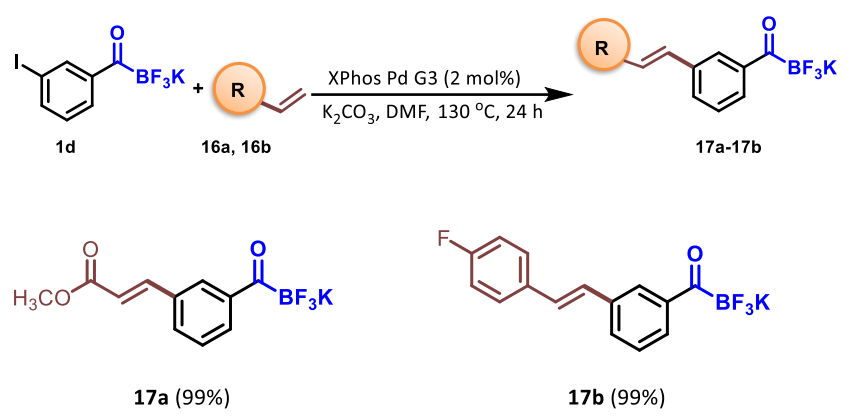

Reaction conditions: KAT 1d ( $0.15 \mathrm{mmol})$, alkene 16 (1.5 equiv.), XPhos Pd G3 ( 2 mol\%), potassium carbonate (3.0 equiv), DMF ( $2 \mathrm{~mL}), 130{ }^{\circ} \mathrm{C}, 24 \mathrm{~h}$.

Scheme 4 Heck reactions on KAT 1d

Further investigations revealed that the KAT building block 1d was also compatible with Heck coupling conditions. Methyl acrylate 16a and 4-fluorostyrene $16 \mathrm{~b}$ furnished the corresponding products $17 \mathrm{a}$ and $17 \mathrm{~b}$ in quantitative yields (Scheme 4) in the presence of a 2 mol\% of XPhos Pd G3 and $\mathrm{K}_{2} \mathrm{CO}_{3}$ in DMF at $130{ }^{\circ} \mathrm{C}$. It is noteworthy that the KAT functionality was found to be stable even when the reaction was heated at $130{ }^{\circ} \mathrm{C}$ under basic conditions.

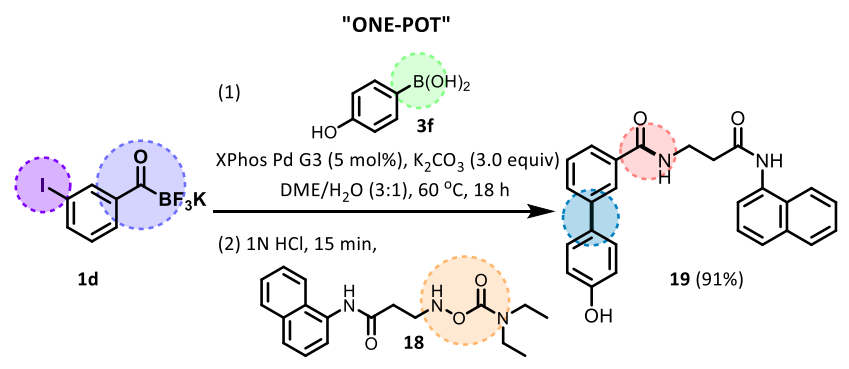

Scheme 5 One-pot chemoselective Suzuki cross-coupling/KAT ligation sequence

Having successfully demonstrated four different types of Pd-catalyzed chemoselective cross-couplings using pre-functionalized KAT building blocks, we extended our approach to a one-pot Suzuki crosscoupling and KAT ligation sequence (Scheme 5). KAT 1d was coupled to 4-hydroxyphenyl boronic acid 3f, 
and the crude cross-coupled product was treated directly with hydroxylamine $\mathbf{1 8}$ under acidic conditions to obtain the desired amide 19 in $91 \%$ yield. This one-pot synthesis further adds to the utility of the building block approach.

\section{CONCLUSION}

In summary, robust strategies to access diverse arrays of KATs have been developed. Optimized conditions were identified to maintain the $C-B$ bond of the KAT functionality completely intact under several different $\mathrm{Pd}$-catalyzed cross-coupling approaches, thus forging various new connections, including $\mathrm{C}\left(\mathrm{sp}^{2}\right)$ $C\left(s p^{2}\right)$ (aryl), $C\left(s p^{2}\right)-N, C\left(s p^{2}\right)-C(s p)$, and $C\left(s p^{2}\right)-C\left(s p^{2}\right)$ (alkene) bonds, to the KAT building blocks in a chemoselective and late-stage fashion. These approaches significantly expand the access to many different types of KATs that are previously unknown, including multi-functionalized (hetero)aryl KATs, bifunctional KATs that can undergo double chemoselective transformations, KAT-functionalized complex molecules, and scaffolds of importance in pharmaceutical and materials science. As these approaches are robust and enable rapid diversification from commercially available KAT building blocks, we envisage the adoption and use of these KATs in a variety of research areas including fragment-based drug discovery and medicinal chemistry.

\section{ACKNOWLEDGEMENT}

RS acknowledges the School of Pharmaceutical Science and Technology (SPST), Tianjin University and the Tianjin Young 1000-Talents Program for the funding support. The authors thank Dr. Xinghua Jin, Ms Gao Yan and Ms Shuyu Yang (Instrumental Analysis Center of SPST, Tianjin University) for their help with recording ${ }^{11} \mathrm{~B}$ NMR and HRMS spectra. The authors also thank Dr Subramanian Govindan for insightful discussions on KATs.

\section{CONFLICTS OF INTEREST}

There are no conflicts to declare.

\section{REFERENCES}

(1) (a) Noda, H.; Bode, J. W. Synthesis and Reactivities of Monofluoro Acylboronates in Chemoselective Amide Bond Forming Ligation with Hydroxylamines. Org. Biomol. Chem. 2016, 14, 16-20. (b) Wu, D.; Taguchi, J.; Tanriver, M.; Bode, J. W. Synthesis of Acylboron Compounds. Angew. Chem. Int. Ed. 2020, 59, 16847-16858. (c) Scharnagl, F. K.; Bose, S. K.; Marder, T. B. Acylboranes: Synthetic Strategies and Applications. Org. Biomol. Chem. 2017, 15, 1738-1752. (d) St. Denis, J. D.; He, Z.; Yudin, A. K. Amphoteric $\alpha$-Boryl Aldehyde Linchpins in the Synthesis of Heterocycles. ACS Catal. 2015, 5, 5373-5379. (e) Šterman, A.; Sosič, I.; Gobec, S.; Časar, Z. Recent Advances in the Synthesis of Acylboranes and Their Widening Applicability. ACS Omega 2020, 517868.

(2) (a) Dumas, A. M.; Bode, J. W. Synthesis of Acyltrifluoroborates. Org. Lett. 2012, 14, 2138-2141. (b) Erős, G.; Kushida, Y.; Bode, J. W. A Reagent for the One-Step Preparation of Potassium Acyltrifluoroborates (KATs) from Aryl- and Heteroarylhalides. Angew. Chem. Int. Ed. 2014, 53, 7604-7607. (c) Liu, S. M.; Wu, D.; Bode, J. W. One-Step Synthesis of Aliphatic Potassium Acyltrifluoroborates (KATs) from Organocuprates. Org. Lett. 2018, 20, 2378-2381. (d) Wu, D.; A Fohn, N.; W. Bode, J. Catalytic Synthesis of Potassium Acyltrifluoroborates (KATs) by Chemoselective Cross-Coupling with a Bifunctional Reagent. Angew. Chem. Int. Ed., 2019, 58, 11058-11062. (e) Molander, G. A.; Raushel, J.; Ellis, N. M. Synthesis of an Acyltrifluoroborate and Its Fusion with Azides To Form Amides. J. Org. Chem. 2010, 75, 4304-4306. (f) Taguchi, J.; Takeuchi, T.; Takahashi, R.; Masero, F.; Ito, H. Concise Synthesis of Potassium Acyltrifluoroborates from Aldehydes through Copper(I)-Catalyzed 
Borylation/Oxidation. Angew. Chem. Int. Ed. 2019, 58, 7299-7303.

(3) (a) Dumas, A. M.; Molander, G. A.; Bode, J. W. Amide-Forming Ligation of Acyltrifluoroborates and Hydroxylamines in Water. Angew. Chem. Int. Ed. 2012, 51, 5683-5686. (b) Noda, H.; Erös, G.; Bode, J. W. Rapid Ligations with Equimolar Reactants in Water with the Potassium Acyltrifluoroborate (KAT) Amide Formation. J. Am. Chem. Soc. 2014, 136, 5611-5614. (c) Saito, F.; Noda, H.; Bode, J. W. Critical Evaluation and Rate Constants of Chemoselective Ligation Reactions for Stoichiometric Conjugations in Water. ACS Chem. Biol. 2015, 10, 1026-1033.

(4) Shiro, T.; Schuhmacher, A.; Jackl, M. K.; Bode, J. W. Facile Synthesis of $\alpha$-Aminoboronic Acids from Amines and Potassium Acyltrifluoroborates (KATs) via Trifluoroborate-iminiums (TIMs). Chem. Sci. 2018, 9, 5191-5196.

(5) (a) Mazunin, D.; Bode, J. W. Potassium Acyltrifluoroborate (KAT) Ligations are Orthogonal to Thiol-Michael and SPAAC Reactions: Covalent Dual Immobilization of Proteins onto Synthetic PEG Hydrogels. Helv. Chim. Acta. 2017, 100, e1600311. (b) White, C. J.; Bode, J. W. PEGylation and Dimerization of Expressed Proteins under Near Equimolar Conditions with Potassium 2-Pyridyl Acyltrifluoroborates. ACS Cent. Sci. 2018, 4, 197206. (c) Schauenburg, D.; Osuna Gálvez, A.; Bode, J. W. Covalently Functionalized Amide Cross-linked Hydrogels from Primary Amines and Polyethylene Glycol Acyltrifluoroborates (PEG-KATs). J. Mater. Chem. B. 2018, 6, 4775-4782. (d) Mazunin, D.; Broguiere, N.; Zenobi-Wong, M.; Bode, J. W., Synthesis of Biocompatible PEG Hydrogels by pH-Sensitive Potassium Acyltrifluoroborate (KAT) Amide Ligations. ACS Biomater. Sci. Eng. 2015, 1, 456-462. (e) Schauenburg, D.; Divandari, M.; Neumann, K.; Spiegel, C. A.; Hackett, T.; Dzeng, Y.-C.; Spencer, N. D.; Bode, J. W. Synthesis of Polymers Containing Potassium Acyltrifluoroborates (KATs) and Postpolymerization Ligation and Conjugation. Angew. Chem. Int. Ed. 2020, 59, 14656-14663. (f) Osuna Gálvez, A.; Bode, J. W. Traceless Templated Amide-Forming Ligations. J. Am. Chem. Soc. 2019, 141, 8721- 8726. (g) Bode, J. W.; Song, H.; Wu, D.; Mazunin, D.; Liu, S. M.; Sato, Y.; Broguiere, N.; Zenobi-Wong, M. Post-assembly Photomasking of Potassium Acyltrifluoroborates (KATs) for Two-Photon 3D Patterning of PEG-Hydrogels", Helv. Chim. Acta. 2020, doi.org/10.1002/hlca.202000172.

(6) (a) Goldberg, F. W.; Kettle, J. G.; Kogej, T.; Perry, M. W. D.; Tomkinson, N. P. Designing Novel Building Blocks is an Overlooked Strategy to Improve Compound Quality. Drug Discov. Today 2015, 20, 11-17. (b) O’Connor, C. J.; Beckmann, H. S. G.; Spring, D. R. Diversity-oriented synthesis: producing chemical tools for dissecting biology. Chem. Soc. Rev. 2012, 41, 4444-4456. (c) Galloway, W. R. J. D.; Isidro-Llobet, A.; Spring, D. R. Diversity-oriented synthesis as a tool for the discovery of novel biologically active small molecules. Nat. Commun., 2010, 1:80. (d) Srinivasan, R.; Li, J.; Ng, S. L.; Kalesh, K. A.; Yao, S. Q. Methods of Using Click Chemistry in the Discovery of Enzyme Inhibitors. Nat. Protoc. 2007, 2, 2655-2664. (e) Abell, C.; Dagostin, C. Fragment-Based Drug Discovery; RSC Publishing: Cambridge, 2015.

(7) (a) Campos, J.; Aldridge, S. Catalytic Borylation Using an Air-Stable Zinc Boryl Reagent: Systematic Access to Elusive Acylboranes. Angew. Chem. Int. Ed. 2015, 54, 14159-14163. (b) Yamashita, M.; Suzuki, Y.; Segawa, Y.; Nozaki, K., Synthesis, Structure of Borylmagnesium, and Its Reaction with Benzaldehyde to Form Benzoylborane. J. Am. Chem. Soc. 2007, 129, 9570-9571.

(8) (a) He, Z.; Trinchera, P.; Adachi, S.; St. Denis, J. D.; Yudin, A. K. Oxidative Geminal Functionalization of Organoboron Compounds. Angew. Chem. Int. Ed. 2012, 51, 11092-11096. (b) Adachi, S.; Liew, S. K.; Lee, C. F.; Lough, A.; He, Z.; Denis, J. D. S.; Poda, G.; Yudin, A. K. Condensation-Driven Assembly of Boron-Containing Bis(Heteroaryl) Motifs Using a Linchpin Approach. Org. Lett. 2015, 17, 5594-5597. (c) Lepage, M. L.; Lai, S.; Peressin, N.; Hadjerci, R.; Patrick, B. O.; Perrin, D. M. Direct Access to MIDA Acylboronates through Mild Oxidation of MIDA Vinylboronates. Angew. Chem. Int. Ed. 2017, 56, 15257-15261. (d) Lin, S.; Wang, L.; Aminoleslami, N.; Lao, Y.; Yagel, C.; Sharma, A. A Modular and Concise Approach to MIDA Acylboronates via Chemoselective Oxidation of Unsymmetrical Geminal Diborylalkanes: Unlocking Access to a Novel Class of Acylborons. Chem. Sci. 2019, 10, 4684-4691.

(9) Tan, D.-H.; Cai, Y.-H.; Zeng, Y.-F.; Lv, W.-X.; Yang, L.; Li, Q.; Wang, H. Diversity-Oriented Synthesis of $\alpha$ Functionalized Acylborons and Borylated Heteroarenes by Nucleophilic Ring Opening of $\alpha$ Chloroepoxyboronates. Angew. Chem. Int. Ed. 2019, 58, 13784-13788.

(10) Cheng, L.-J.; Zhao, S.; Mankad, N. P. One-Step Synthesis of Acylboron Compounds via Cu-Catalyzed Carbonylative Borylation of Alkyl Halides. Angew. Chem. Int. Ed. 2020, doi.org/10.1002/anie.202012373. 